\title{
The Future of Energy
}

Fabio Polonara

Dipartimento di Ingegneria Industriale e Scienze Matematiche (DIISM), Università Politecnica delle Marche, via Brecce Bianche, Ancona 60131, Italy

Corresponding Author Email: f.polonara@univpm.it

https://doi.org/10.18280/ti-ijes.640102

Received: 17 August 2019

Accepted: 8 February 2019

\section{Keywords:}

energy, renewables, fossil fuels, increasing and decreasing returns, research \& development

\begin{abstract}
While the European Union is preparing its Green New Deal, whichever it will be, the energy sector is moving, anyway, towards its transition.

The so-called "energy transition" is dictated by the fact that energy is reckoned as one of the main responsible for climate change and by the awareness that the era of fossil fuels is approaching its end.

To better define the energy transition, some points that are expected to characterize the passage from fossil fuels to renewables are explored in the paper.
\end{abstract}

\section{INTRODUCTION}

While the European Union is preparing its Green New Deal, whichever it will be, the energy sector is moving, anyway, towards its transition.

The so-called "energy transition" is dictated by the fact that energy is reckoned as one of the main responsible for climate change and by the awareness that the era of fossil fuels is approaching its end.

To better define the energy transition, we will try to explore the following points:

- Fossil fuels are going to be replaced by renewable energies, which are mature both technically and economically;

- Renewable energies mean "increasing returns", fossil fuels (and also nuclear) mean "decreasing returns": this is why there is no other way out;

- Policy actions are needed to accompany the transition, and they can be implemented only after politicians have been convinced that they are inevitable;

- Research \& Development (R\&D) must be encouraged along with policy choices;

- Environmentalists must support renewable energy even if it has a certain impact, which is, anyway, much lower than the impact linked with all the other options.

\section{RENEWABLE ENERGIES VS FOSSIL FUELS}

It is well known that the energy sector is one of the main responsible for the emission of greenhouse gases, in particular carbon dioxide, into the atmosphere. This responsibility is due to the widespread use of fossil fuels for all the energy needs: Power plants, transport, industry, residential and commercial uses.

But fossil fuels are closely linked (even more than we think) to modern societies as we know them today. Almost every activity: (commerce, industry, agriculture, tourism, transport) exists with the fundamental contribution of fossil fuels.

So, getting rid of them is easily said but not easily done.
Many experts think that abandoning fossil fuels (either voluntarily or by force) would mean the end of contemporary advanced societies and we would be driven back into some revisited middle ages [1].

Perhaps there is a less catastrophic and more optimistic view. It is the one that considers renewable energies capable, in a few decades, of completely replacing fossil fuels for almost all energy uses.

Making a substantial contribution to the solution (a partial one, at least) of the problems related to greenhouse gases emissions.

Energy used on Earth comes essentially from the Sun, either that arriving instant by instant in the form of thermal radiation and that accumulated during thousands of years in the form of fossil fuels (which we are now consuming at high speed).

The energy sent from Sun to Earth, as short-wavelenght radiation (about $4 \cdot 10^{24} \mathrm{~J}$ per annum [2]) is able to cover, in one hour, the yearly energy needs of the modern world (which is of the order of $0.5 \cdot 10^{21} \mathrm{~J}$ per annum [2]).

Thinking in percentage terms, we can say that it would be enough to capture $0.015 \%$ of the incoming solar radiation to completely satisfy our requirements.

From these figures one understands that it is not a matter of energy balance (the energy that comes from the Sun is much more than we need): it is purely an engineering problem (ability to intercept that energy, which is widespread in time and space, and to make it usable for the needs of mankind) and an economic one (ability to intercept that energy at a lower cost than using other sources, such as fossil energy).

On technical grounds, some of the major issues have been largely resolved and today renewable energies could already gather the legacy of fossil fuels both from a technological and an economic point of view.

In an article published in 2017 by some American scientists [3], a roadmap was drawn up for the replacement of $100 \%$ of fossil fuels with renewable energy in 139 of the most important countries on the planet from now until 2050.

That roadmap is entirely feasible and leads, in addition to a huge result in environmental terms, to another incredible result: 
abandoning fossil fuels would lead, at global level, to the loss of 28 million jobs but at the same time the widespread adoption of renewable energies would allow the creation of 52 million new jobs, with a net benefit of 24 million jobs.

\section{DECREASING RETURNS VS INCREASING RETURNS}

In fact, other than technical, the reason why the transition from the fossil era to the renewable era is bound for happening, no matter what, is substantially economic.

This statement can be explained based on the fact that the development of renewable energies feature "increasing returns" (the more the exploitation of renewable energies is increased, the more one earns) while the entire fossil fuels sector features "decreasing returns" (the more the exploitation of fossil energies is increased the less it is earned).

Actually, if the oil\&gas global demand increases, new sources will have to be found and exploited. It is well known that the exploitation of new oil\&gas reserves is more and more expensive while old and easy wells are being depleted and new wells have to be put in production, which are located in remote areas of the globe (such as the Arctic) or in deep offshore trenches.

This means that if the global oil\&gas demand arises, the supply costs are going to arise at a faster pace and the industry returns are going to decrease, provided that one wants to maintain the energy price at a popular level.

The same pattern can be applied to coal and also to nuclear sources.

On the contrary, renewable energies are subject to Moore's law [4], like Information Technology (IT) devices, and are governed by the "increasing returns" pattern.

As a matter of fact, PV technology, for example, have a learning curve of $22 \%$, which means that their selling prices have dropped by $22 \%$ for every doubling of cumulative production volume (see Figure 1).

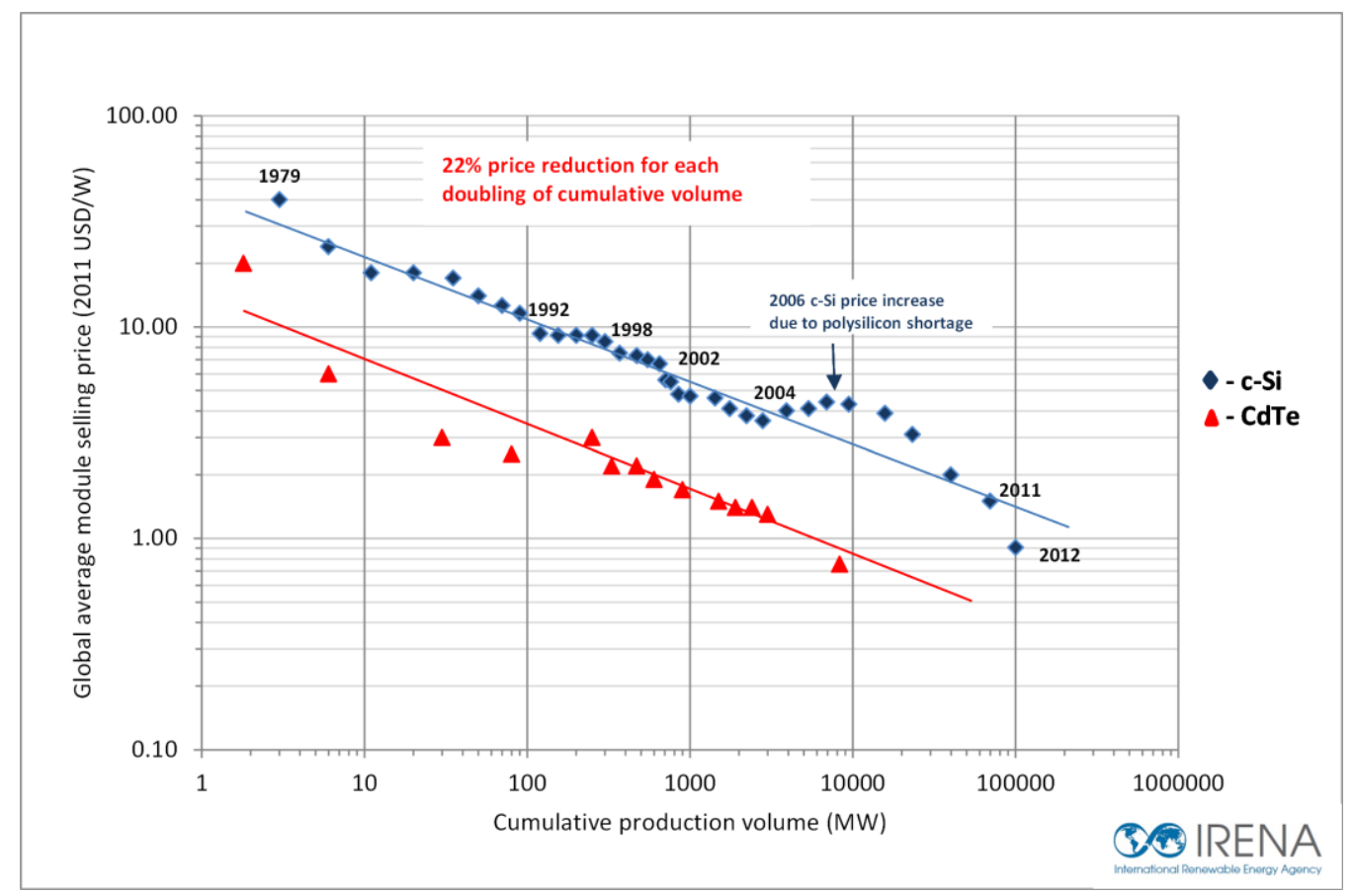

Figure 1. Learning curve of PV technology (IRENA, [5])

The more demand there is in the market, the less is the price that the final user has to pay to install a PV plant. One good feature of this framework is that an increase of the demand somewhere in the world causes a reduction of selling prices everywhere, not only where the demand increase has happened. This beneficial arrangement yields, at the end of the day, to increasing returns for the whole chain.

Something that is expected to continue for the foreseeable future.

It seems clear, at this point, that the real problem of energy transition, the transition from fossil fuels to renewable energy, is neither technical nor economic.

It is basically political; and it is relying on political choices.

\section{THE ROLE OF POLICIES}

Even if the technical and economic contexts are favorable, a rapid and widespread implementation of renewables energies is not granted.

Vested interests that are against an easy deployment of renewable technologies are so many and so strong that something more is needed: market forces alone are not enough.

Politics have to be involved: Only if politicians get convinced that, paving the road for renewables energies, they act against the climate change and build the future of the planet while, at the same time, maintaining their chances to be reelected at the next elections, then there is hope that something will be done.

Politicians need to be convinced. This is where movements like "Fridays for Future" enter the picture. Young Greta Thunberg's huge merit is to have raised, to a level that no scientist has been able to do so far, the awareness that something has to be done and has to be done now.

The Time magazine cover and the " 2019 person of the year" award are more than deserved.

Hopefully, listening to Greta Thunberg, some politicians will decide that it is time to intervene and to clear the path to 
market forces to start what they are ready to do in favor of an actual energy transition.

Making public opinion aware of the emergency is a fundamental step in order to convince politicians to start acting. If Greta accomplishes that task, she will have obtained something that science has not been able to achieve.

\section{THE ROLE OF SCIENCE}

Nevertheless, the role of science remains fundamental.

Renewable energies have enjoyed important product and process innovation that have brought their costs to levels completely comparable with those of fossil fuels.

But a lot of work in research and development is still needed, both in the field of energy production and in the field of end uses.
This is largely due to the characteristics of renewable energy, too widespread over time and space to be easily used. Exactly the contrary of fossil fuels, which concentrate large amounts of energy in small amounts of mass and volume.

Few examples can explain how much R\&D work has already been done and how much it is still needed to make the technology as user friendly as possible.

First of all, from improvements in materials for photovoltaic conversion of solar energy one can see how much has already been done. Actually R\&D on PV materials has guaranteed a great increase in efficiencies and an extraordinary decrease in costs. Figure 2 shows the trend, over the years, of PV cell efficiencies. It is evident the dramatic growth in efficiency that the PV technology has undergone in the last 40 years.

On the other hand, the case of energy storage (and of electric batteries, of course) is emblematic of the fact that, even if a lot of work has already been done, there is still a lot of work to do.

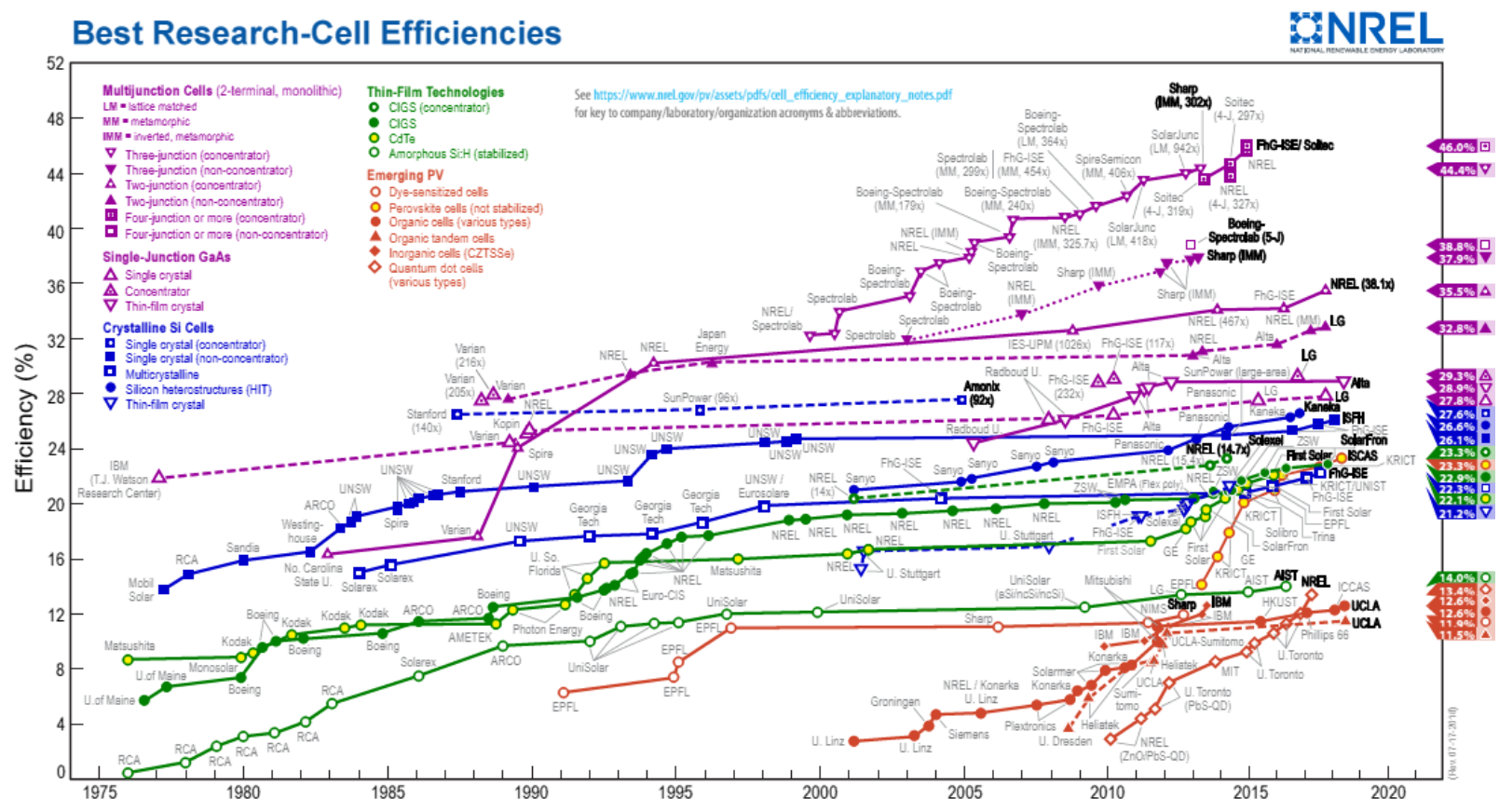

Figure 2. Trend of PV research-cell efficiencies over the years (NREL, [6])

Figure 3 shows the status of the different technologies for energy storage under investigation in terms of readiness level.

Speaking of things to do, one must not forget the problem of rare earths, which are not so abundant on the planet and may cause supply shortages in the future, if R\&D does not find new solutions more easily available.

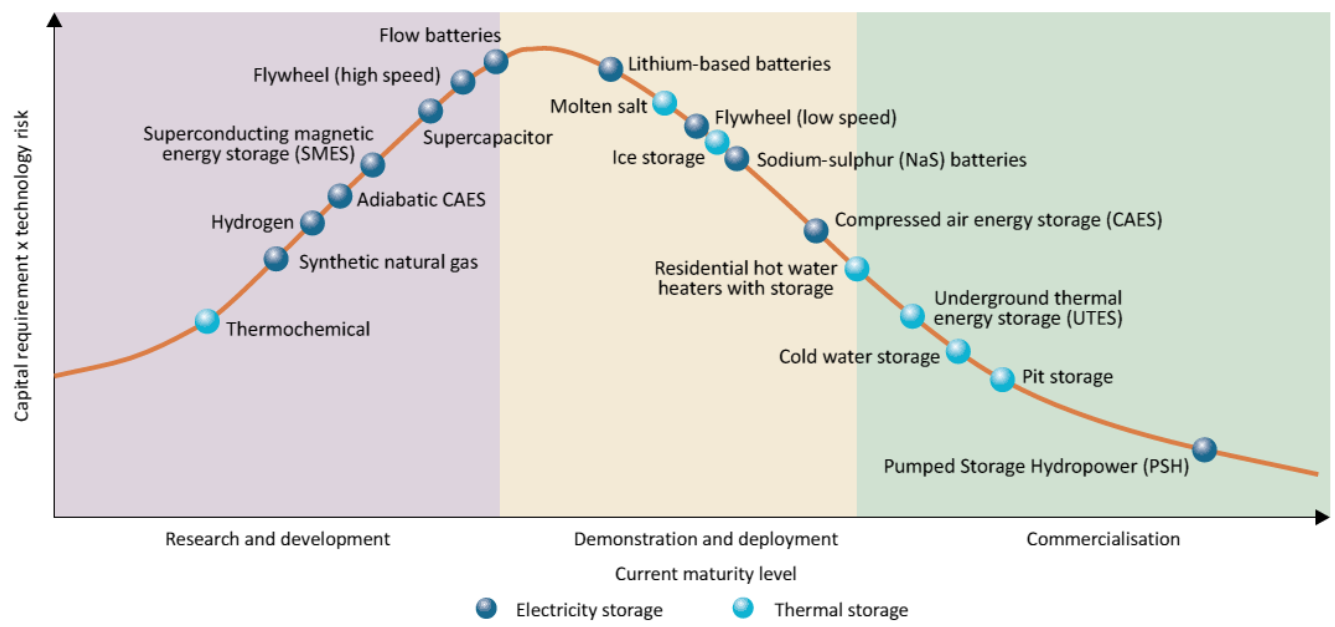

Figure 3. Readiness level of energy storage technologies [7] 
In essence, together with a 180-degree reversal of the political choices in favor of renewable energy, the other fundamental aspect is the support to research and development activities because the margins for improvement of all the technologies are appalling, and continuing to work in this direction could have unexpected results in a few years.

\section{CONCLUSIONS}

There is one further aspect, worth analyzing in the context of renewable energies development. It is the role of environmental movements (the people whose antagonists contemptuously call "tree huggers").

It may seem unbelievable but the main opponents of a radical change in the energy paradigm are very often the environmental movements.

According to the logic of the "NIMBY syndrome" (Not In My Back Yard), and also of the "BANANA syndrome" (Build Absolutely Nothing Anywhere Near Anything), those who dispute the installations of renewable energy, wind, photovoltaic, biomasses, are most often the environmental movements based on the territories where the change is going to happen.

We are well aware that any energy installation, without exception, have a certain environmental impact.

However, it is time to line up and compare these impacts. Which are not all the same.

In fact, the environmental impact of a wind farm, although it exists (on the landscape, on the fauna and on the acoustics), is always much lower than that of any fossil fuel power plant.

We cannot be very optimistic, but I strongly believe that a possible (though difficult) solution to the problem of climate change passes, without alternatives, to the change in the energy paradigm.

In other words, from the decarbonisation of the energy sector and its urgent and total conversion to renewable technologies. If we want to save the planet, we cannot avoid converting the energy paradigm. It is time to make choices. And to make, now, the right ones.

\section{REFERENCES}

[1] Arteconi, A., Caresana, F., Cesini, G., Comodi, G., Corvaro, F., D’Alessandro, V., Di Nicola, G., Latini, G., Pacetti, M., Paroncini, M., Passerini, G., Pelagalli, L., Polonara, F., Ricci, R. (2019). Energy scenarios for the future of mankind. The First Outstanding 50 Years of "Università Politecnica delle Marche", 223-246. https://doi.org/10.1007/978-3-030-32762-0_13

[2] Smil, V. (2007). Energy in Nature and Society, MIT Press, Cambridge, Mass., p. 29, ISBN: 978-02-6269356-1

[3] Jacobson, M.Z., Delucchi, M.A., Bauer, Z.A.F., Goodman, S.C., Chapman, W.E., Cameron, M.A., Bozonnat, C., Chobadi, L., Clonts, H.A., Enevoldsen, P., Erwin, J.R., Fobi, S.N., Goldstrom, O.K., Hennessy, E.M., Liu, J.Y., Lo, J., Meyer, C.B., Morris, S.B., Moy, K.R., O'Neill, P.L., Petkov, I., Redfern, S., Schucker, R., Sontag, M.A., Wang, J.F., Weiner, E., Yachanin, A.S. (2017). 100\% clean and renewable wind, water, and sunlight all-sector energy roadmaps for 139 countries of the world. Joule, 1(1): 108-121. http://dx.doi.org/10.1016/j.joule.2017.07.005

[4] Moore's law, https://en.wikipedia.org/wiki/Moore\%27s_law, accessed on Dec. 24, 2019.

[5] International Renewable Energy Agency, IRENA, http://www.irena.org//media/Images/IRENA/Costs/Chart/Solarphotovoltaic/fig-62.png, accessed on Dec. 24, 2019

[6] National Renewable Energy Laboratory, NREL, https://www.nrel.gov/pv/assets/pdfs/pv-efficiencies-0717-2018.pdf, accessed on Nov. 17, 2018

[7] EASE-EERA. (2018). European Energy Storage Technology Development towards 2030 - Update. https://www.eera-set.eu/wp-content/uploads/ 2017.01.16_Update-of-the-EASE-EERA-ESTechnology-Development-Roadmap_for-publicconsultation.pdf, accessed on Nov. 17, 2018. 